\title{
Diversity in fall characteristics hampers effective prevention: the precipitants, the environment, the fall and the injury
}

\author{
K. M. Sanders ${ }^{1}$ - K. Lim ${ }^{1}$ - A. L. Stuart ${ }^{2}$ A. Macleod ${ }^{1}$ - D. Scott ${ }^{3}$ - G. C. Nicholson ${ }^{4}$ • \\ L. Busija ${ }^{1}$
}

Received: 19 January 2017 / Accepted: 4 July 2017 / Published online: 19 July 2017

(C) The Author(s) 2017. This article is an open access publication

\begin{abstract}
Summary Falls among the elderly are common and characteristics may differ between injurious and non-injurious falls. Among 887 older Australian women followed for 1.6 years, $32 \%$ fell annually. Only $8.5 \%$ resulted in fracture and/or hospital admission. The characteristics of those falls are indistinguishable from those not coming to medical attention.

Introduction The precipitants and environment of all falls occurring among a large cohort of older Caucasian women were categorised by injury status to determine if the characteristics differed between injurious and non-injurious falls.

Methods Among 887 Australian women (70+ years), falls were ascertained using monthly postcard calendars and a questionnaire was administered for each fall. Hospital admissions and fractures were independently confirmed.

Results All falls were reported for a mean observation time of 577 (IQR 546-607) days per participant, equating to a total 1400 person-years. Thirty-two percent fell at least once per year. The most common features of a fall were that the faller was walking $(61 \%)$ at home $(61 \%)$ during the day $(88 \%)$ and lost balance (32\%). Only $12 \%$ of all falls occurred at night. Despite no difference in the type of injury between day and night, the likelihood of being hospitalised from a fall at night
\end{abstract}

K. M. Sanders

kerrie.sanders@acu.edu.au

1 Institute for Health \& Ageing, Australian Catholic University, Level 6, 215 Spring Street, Melbourne 3000, Australia

2 Deakin University, Geelong, Australia

3 School of Clinical Sciences at Monash Health, Monash University, Melbourne, Australia

4 Rural Clinical School, School of Medicine, The University of Queensland, Toowoomba, Australia was 4.5 times greater than that of a daytime fall with adjustment for injury type and participant age (OR 4.5, 95\% CI 2.1, 9.5; $p<0.001)$. Of all falls, approximately one third were associated with no injury to the faller $(31 \%)$, one third reported a single injury (37\%) and one third reported more than one injury (32\%). In $95 \%$ of falls, the faller was not admitted to hospital. Only $5 \%$ of falls resulted in fracture(s).

Conclusions Our findings demonstrate the significant diversity of precipitants and environment where falls commonly occur among older community-dwelling women. Falls resulting in fracture and/or hospital admission collectively represent $8.5 \%$ of all falls and their characteristics are indistinguishable from falls not coming to medical attention and incurring no apparent cost to the health system.

Keywords Fall $\cdot$ Fall environment $\cdot$ Fall injury precipitants · Fracture $\cdot$ Older women

\section{Introduction}

Falls in community-dwelling older adults represent an expanding public health problem. Hospital admissions, morbidity and mortality and the associated costs due to falls continue to grow as longevity increases. In Australia in 2011, falls were ranked 18th in the national ranking of non-fatal burden, an increase from 23rd in 2003 [1]. The annual number of hospital inpatient days in Australia for fall injury in older people increased by one third over the 12 years from 1999/ 00 to 2010/11 [2] and the mean length of stay (LOS) in hospital for fall injury is 7.0 days [3] compared to 4.5 days for all conditions in the same age group [4]. Much public health research has focussed on the development of interventions aiming to minimise falls risk through potentially modifiable risk factors [5]. This is particularly relevant to osteoporosis 
and fracture prevention since a majority of fractures are associated with a fall, including over $90 \%$ of all hip fractures [6]. Furthermore, despite measures to reduce fracture risk through pharmaceutical anti-osteoporosis treatment, uptake continues to be extremely low [7].

Despite a decrease in the rate of hip fractures, the actual number of adults with hip fractures continues to increase $[8$, 9]. Hip fractures represent one of the most serious consequences of fall injury and are a major contributor to the hospital LOS (hip fracture LOS, 14.7 days in 2010/11) [2]. Increasingly, clinical guidelines for fracture risk assessment are incorporating an estimate of falls risk [10-13]. However, quantifying falls risk in older individuals continues to lack sufficient accuracy around achieving adequate positive and negative predictive values from the one tool. A systematic review of screening tools for predicting falls concluded that insufficient evidence exists that any screening tool can adequately predict falls [14]. Of the 29 included tools, only two had evidence that their sensitivity and specificity both exceeded $80 \%$ [14].

The majority of falls in the elderly occur not as a result of substantial risk associated with any one factor but rather several smaller risk factors synergistically increasing an individuals' falls risk [15]. Identifying the circumstances and characteristics of falls could improve efficacy of prevention strategies by targeting the most common features of falls associated with morbidity.

Few, if any recent studies have identified the precipitants and environment of all falls occurring among a large group of older women [16-18]. Most have limited ascertainment to patients presenting at emergency departments and/or hospital admission for falls $[19,20]$. While this represents an economical way to ascertain the falls associated with the highest health service costs, it is not known if these falls represent typical circumstances. Furthermore, these studies do not provide any information on fall rates among the elderly. Understanding precipitants of falls among older women is particularly relevant since two thirds of fragility fractures occur in women and a majority of these fractures are associated with a fall [21]. We aimed to quantify the total number of all falls that occurred in a large cohort of older Caucasian women and determine the proportion of falls that resulted in a hospital presentation. We hypothesised that the characteristics of falls may differ between injurious and non-injurious falls. This study describes the precipitants and environment of all falls and associated prevalence of injury among a large group of Australian women aged at least 70 years, who were prospectively followed for a median of 1.6 years.

\section{Methods}

The current study was part of the Vital D study: a doubleblind, randomised, placebo-controlled trial (RCT) involving women aged 70 years or older residing in southern Victoria, Australia (latitude $38^{\circ} \mathrm{S}$ ). The primary outcome was falls and fractures and recruitment methods have been published previously $[22,23]$. The participants were identified from the Australian Electoral Commission's electoral roll. Voting is compulsory in Australia for all persons aged 18 years and over. All women aged 70 years or older on the electoral roll of the region were sent an invitation [22]. Participants were community-dwelling women identified as being at higher risk of fracture through the use of an eligibility algorithm adapted from risk factors for hip fracture including maternal hip fracture, past fracture or self-reported faller. The study was approved by the ethics boards of Barwon Health, Geelong and The University of Melbourne. All participants provided written informed consent prior to being randomised to a large annual oral dose of vitamin D or placebo [22]. If they were unable to cognitively cope with the demands of the study, they were withdrawn. The study coordinator conducting the phone interviews about fall circumstances was able to exclude participants who she considered to be confused regarding their reporting of the falls characteristics. We have previously published some indices of mental well-being [24].

The current analysis uses data collected from participants randomised to placebo with complete falls data $(n=1125)$. Participants recorded falls and fractures using postcard calendars. The calendars were completed daily by writing $F$ if they had a fall or fracture, or both, and $N$ if they did not, and were returned monthly by prepaid post. Participants unable to send the postcards were telephoned monthly. Falls were defined as "an event reported either by the faller or a witness, resulting in a person inadvertently coming to rest on the ground or another level, with or without loss of consciousness or injury" [25]. This definition was explained to participants and reinforced twice yearly via newsletter.

When a fall or fracture was documented, a follow-up questionnaire to ascertain the circumstance of the fall was administered by telephone. All hospital admissions were confirmed using hospital records and all fractures were radiologically confirmed. Participants were telephoned within the first 2 weeks following the end of any month. Falls were classified as "resulting from active behaviour" when the participant, at the time of the fall, was walking, gardening, shopping, doing housework, engaging in sports, rushing or climbing a ladder or chair. Other circumstances surrounding falls were classified as non-active behaviour. Participants were asked to describe where they were when they fell as an open-ended question, and it was noted whether the fall occurred outdoors or indoors. They were also asked to describe any warning signs prior to the fall (e.g. dizziness, feeling unwell, feeling unsteady). To ascertain whether any non-fracture injuries resulted from the fall, participants were asked whether they sustained any bruises, muscle strains, abrasions or any other injuries. Irrespective of whether injuries were sustained, women were 
asked whether they sought any of the following treatments following the fall: doctor visit, hospitalisation, medical imaging, physiotherapy, wound stitching or injury dressing. Women were able to report multiple injuries and treatments from a single fall.

Participants were asked annually to complete a table of current medications. Results from the 2008 medication table were used to assess the prevalence of daily aspirin among the participants. Body mass index (BMI) was calculated from self-reported height and weight $(\mathrm{BMI}=$ weight $[\mathrm{kg}] /$ height $\left[\mathrm{m}^{2}\right]$ ). Previous fracture since the age of 50 years was also self-reported. Midway through the Vital D study (November 2006), the standardised falls/fracture questionnaire was expanded to include information on the time of day (day/night) and lighting (lights on/off). All data used in this analysis relate only to those randomised to placebo for whom we had complete falls ascertainment between the introduction of this expanded falls questionnaire in November 2006 and study completion in 2008. Completion dates in 2008 were staggered as participants finished the study 12 months following their last annual dose of study medication in 2007. Of the 1125 women randomised to the control group, 887 women completed the expanded questionnaire and are included in the analysis. A comparison of those included in falls analysis $(n=887)$ versus not included $(n=238)$ shows no differences (mean [SD]) in (1) age (on 1 November 2006: 78.3 [4.5] vs. 77.1 [5.0] years; $p=0.137$ ) or (2) BMI (26.3 [0.2] vs. $\left.26.1[0.3] \mathrm{kg} / \mathrm{m}^{2} ; p=0.605\right)$; however, fewer women in this study reported having a previous fracture compared to those who did not complete the expanded questionnaire and therefore not included $(n=275 /$ $887(31.4 \%)$ vs. $68 / 237$ (39.1\%), $p=0.048)$.

\section{Statistical analyses}

1. Initial comparisons of participant characteristics of women who fell at least once and those who did not fall were tested using chi-square tests and independent samples $t$ tests or independent samples median tests, as appropriate (Table 1).

2. Participant-level data: To compare participant characteristics (age, BMI and previous fracture) according to the injury type, multilevel multinomial logistic regression models were used to account for the clustering of injuries (level 1) within falls (level 2) and within women (level 3).

3. Participant-level data: Multilevel logistic regression was also used to assess whether the likelihood of a woman being hospitalised was associated with whether the fall occurred during the night or day. Strength of the association was assessed as odds ratios (OR) adjusted for age, type of injury and for repeated falls within the individual.

4. Fall-level data: Comparisons of characteristics of falls between groups (e.g. falls resulting in hospitalisation vs. no hospitalisation; falls during day vs. night) were tested using chi-square or Fisher's exact tests. In this fall-level data, we wanted to present raw data on the characteristics of falls.

Stata/SE 14.0 (StataCorp LP, College Station, TX, USA) and SAS 9.4 (SAS Institute Inc., Cary, North Carolina, USA) were used to analyse the results. $p$ value $<0.05 / 95 \%$ confidence interval (CI) not including null was considered statistically significant. Bonferroni correction was used where multiple comparisons were performed on the same variable.

\section{Results}

Among 887 women with a mean age of 78.3 years (SD 4.5 years; range 72 to 94 years), $32 \%(n=286)$ fell at least once per annum, $12 \%(n=103)$ fell at least twice per annum and $5 \%(n=48)$ fell at least three times per annum. From the total placebo group of 1125 participants, 238 (21\%) did not have complete falls ascertainment from 1 November 2006 to completion in 2008. The groups did not differ in age $(p=0.207)$ or BMI $(p=0.605)$; however, $31 \%$ of the included group reported a previous fracture compared with $39 \%$ of the withdrawn group $(p=0.048)$. When adjusted for age and BMI, this difference was attenuated $(p=0.055)$. Characteristics of 887 women by fall status are described in Table 1. There were 1195 falls during the total follow-up of 1400 person-years, at a rate of 85 falls per 100 person-years.

The most common features of a fall were that the faller was walking $(61 \%)$ at home $(61 \%)$ during the day $(88 \%)$ and lost balance (32\%). The faller fell forwards (62\%) and was able to get up without assistance (66\%; Table 2). The faller sustained bruising (49\%) but did not seek treatment for an injury (69\%). A single injury was (self) reported for $37 \%$ of falls and in $95 \%$ of falls, the faller was not admitted to hospital (Tables 3 and 4).

\section{Precipitants of all falls}

Of the falls that occurred while the faller was walking ( $n=726 / 1195$; Table 2), most involved slipping on an uneven or slippery surface $(29 \%, n=209 / 726)$ or tripping over an obstacle such as shoes, pet, step or gutter $(27 \%, n=198 /$ 726). For approximately one in five of the falls that occurred while walking, the fallers reported that they lost balance or felt dizzy/faint $(22 \%, n=158 / 726)$ immediately before the fall. Relatively few falls involved falling down stairs or missing a step $(6 \%, n=76 / 1195)$.

Gardening was the second most common activity associated with falling, accounting for almost one in ten falls (9\%, $n=104 / 1195)$. Almost half these falls were associated with a loss of balance just before the fall $(47 \%, n=49 / 104)$. Another 
Table 1 Characteristics of women categorised by fall status and injury category

All women $(n=887)$ Participants categorised by fall status

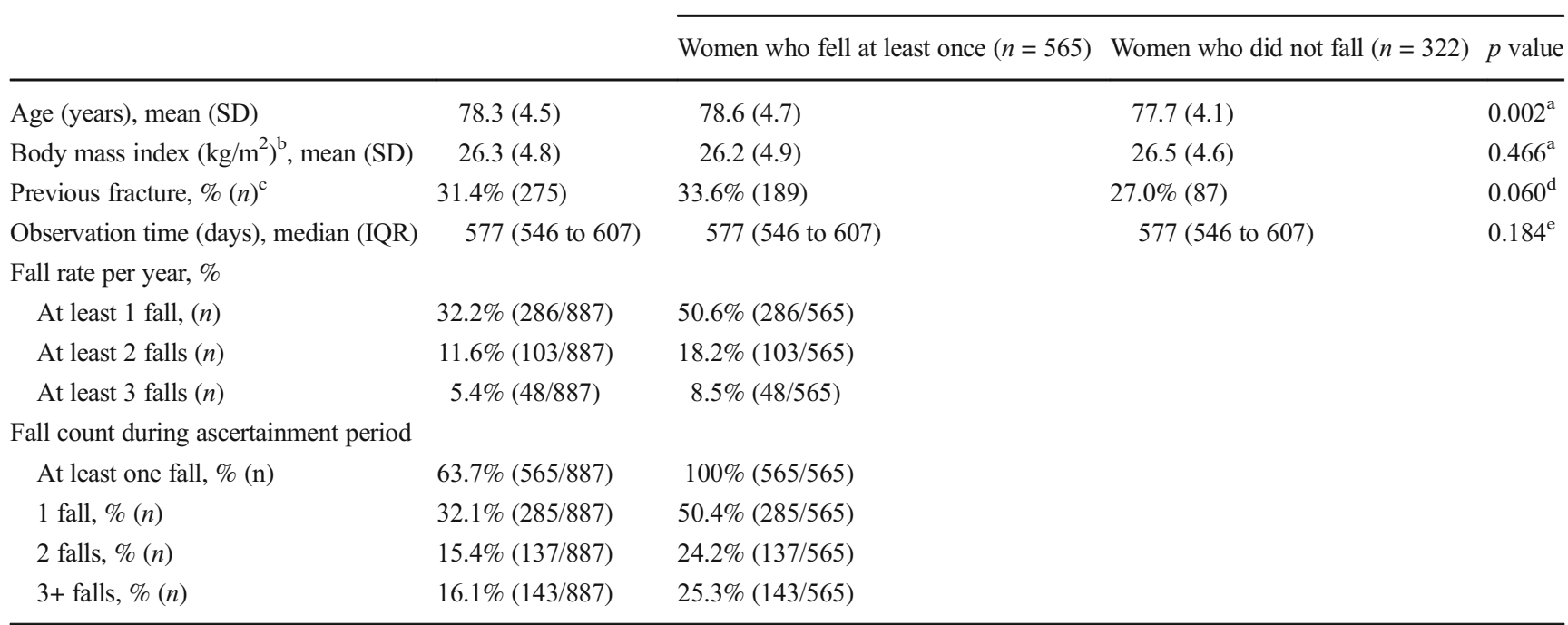

${ }^{\mathrm{a}}$ Independent samples $t$ tests were used to compare women who did and did not fall during observation time

${ }^{\mathrm{b}}$ Ten women (with 25 falls in total) had missing BMI data

${ }^{\mathrm{c}}$ Six women (with 10 falls in total) had missing data regarding fracture history

${ }^{\mathrm{d}}$ Chi-square test was used to compare women who did and did not fall during observation time

${ }^{\mathrm{e}}$ Independent samples median test was used to compare women who did and did not fall during observation time; lower and upper Tukey adjacent values were 516 and 669 in women who fell at least once, and 485 and 669 in women who did not fall

$30 \%$ of fallers occurred due to tripping over an obstacle while gardening $(n=30 / 104)$.

Getting in or out of a bed or chair accounted for only $5 \%$ of all falls $(n=57 / 1195)$. Of these, just over half $(n=30 / 57)$ were associated with loss of balance or dizziness.

\section{The environment of all falls}

Of the falls at home, slightly more occurred inside the house (inside $34 \%$, outside $28 \%$; Fig. 1). Only $7 \%$ of falls occurred in other people's homes $(n=87 / 1195)$ and these occurred almost equally inside and outside the house. Falls occurring in a public place accounted for $27 \%$ of all falls $(n=324 / 1195)$ and more than two thirds of these occurred outdoors (inside $31 \%$; outside $69 \%$; Fig. 1$)$.

Only $12 \%(n=147 / 1195)$ of all falls occurred at night with approximately equal proportions occurring with lights on and off (Table 2). The most common locations for falls at night were in the bedroom $(29 \%, n=43 / 147)$ and outside the house $(14 \%, n=21 / 147)$. Of the 147 night falls, 23/147 (16\%) were falls from a bed/chair or stairs and 124/147 (84\%) were falls in other situations. Bed/chair and stair falls were not more likely to result in hospitalisation than falls occurring in other situations $(9 \%(2 / 23)$ bed/chair/stair falls hospitalised vs. $13 \%(16 /$ 124) other falls).

Only one in five falls involved falling sideways and one in five falls involved falling backwards (Table 2).

\section{Injuries from all falls}

Two thirds of all falls resulted in at least one injury ( $n=821$ / $1195)$, of which $37 \%(n=441 / 1195)$ resulted in a single injury and $32 \%(n=380 / 1195)$ resulted in more than one injury (Table 3).

The most commonly reported injury was bruising (49\%; Table 4), which was not associated with aspirin use. One third of falls that resulted in bruising also had muscle strain (Table 4). Fracture(s) was sustained in 5\% of all falls and the fracture rate associated with falls was 4.5 per 100 personyears. The faller was admitted to hospital in $5 \%$ of all falls. There was no difference in women's age, BMI or history of previous fracture at the time of a fall between falls that sustained fracture(s), non-fracture injury or no injury ( $p=0.567 ; p=0.680 ; p=0.286$, respectively). Only $8.5 \%$ $(n=101 / 1195)$ resulted in fracture and/or hospitalisation.

\section{The precipitants and environment of injurious versus non-injurious falls}

Injury was reported in a higher proportion of falls while walking compared to falls while gardening or falls from the bed or chair (chi-square with Bonferroni adjustment, $p=0.006$ ). Similarly, a higher proportion of injurious falls occurred outdoors and occurred at home (Fig. 2a). 
Table 2 Characteristics of falls based on whether the faller was admitted to hospital (\% (n))

All falls $(n=1195) \quad$ Non-hospitalised falls $(n=1132) \quad$ Hospitalised falls $(n=63) \quad p$ for difference ${ }^{\mathrm{a}}$

Environment

Place of fall

Own home ${ }^{\mathrm{b}}$

Away from home

Fall location

Indoors $^{\mathrm{b}}$

Outdoors $^{\mathrm{b}}$

Time of fall

Day time

Night time

Lighting of night time falls

Night falls with lights on ${ }^{\mathrm{c}}$

Night falls with lights off ${ }^{\mathrm{c}}$

Precipitants/circumstances

Activity when fall occurred

Walking

Gardening

Displacement from quiet position ${ }^{\mathrm{f}}$

Getting in/out of bed or chair

Rushing (e.g. chasing something, answering phone)

Sitting

Standing

Housework

Bending down or reaching up for object

Circumstance of fall

Loss of balance

Tripping

Slipping on obstacle/surface

High risk activity ${ }^{\mathrm{d}}$

Low level fall (from bed/chair)

Pushed/knocked over

Fall direction ${ }^{\mathrm{g}}$

Forwards

Sideways

Backwards

Immediate fall impact

Blacked out ${ }^{\mathrm{h}}$

Could not get up on own

$\begin{array}{ll}61.4 \%(733) & 61.4 \%(694) \\ 38.6 \%(461) & 38.6 \%(437) \\ & \\ 45.3 \%(541) & 44.4 \%(502) \\ 54.7 \%(653) & 55.6 \%(629) \\ & \\ 87.7 \%(1048) & 88.6 \%(1003) \\ 12.3 \%(147) & 11.4 \%(129) \\ & \\ 53.3 \%(73 / 137) & 51.3 \%(61) \\ 46.7 \%(64 / 137) & 48.7 \%(58)\end{array}$

$60.8 \%(726)$

$8.7 \%$ (104)

$13.4 \%(160)$

$4.8 \%$ (57)

$3.6 \%$ (43)

$2.8 \%(33)$

$2.3 \%(27)$

$4.5 \%(54)$

$3.6 \%$ (43)

$31.7 \%(379)$

$23.1 \%(276)$

$23.0 \%(275)$

$9.5 \%(114)$

$2.3 \%(27)$

$2.2 \%(26)$

$61.6 \%(727)$

$19.6 \%(231)$

$18.8 \%(222)$

$2.4 \%(28)$

$34.2 \%(409)$
$60.9 \%(689)$

$8.9 \%(101)$

$12.8 \%(145)$

$4.7 \%(53)$

$3.5 \%$ (39)

$2.5 \%(28)$

$2.2 \%(25)$

$4.6 \%(52)$

$3.8 \%(43)$

$30.2 \%(342)$

$24.2 \%(274)$

$23.4 \%(265)$

$9.6 \%(109)$

$2.3 \%(26)$

$2.2 \%(25)$

$61.3 \%(687)$

$19.6 \%$ (219)

$19.1 \%(214)$

$1.4 \%$ (16)

$31.5 \%(356)$
$61.9 \%(39)$

$38.1 \%$ (24)

$61.9 \%$ (39)

$38.1 \%$ (24)

$71.4 \%$ (45)

$28.5 \%$ (18)

$66.7 \%(12)$

$33.3 \%$ (6)

$58.7 \%(37)$

0.735

$4.8 \%$ (3)

$0.358^{\mathrm{e}}$

$23.8 \%$ (15)

0.013

$6.4 \%$ (4)

$0.537^{\mathrm{e}}$

$6.4 \%$ (4)

$0.280^{\mathrm{e}}$

$7.9 \%$ (5)

$0.026^{\mathrm{e}}$

$3.2 \%$ (2)

$0.650^{\mathrm{e}}$

$3.2 \%$ (2)

$0.999^{\mathrm{e}}$

0

$0.164^{\mathrm{e}}$

$58.7 \%$ (37)

$<0.001$

$3.2 \%$ (2)

$<0.001^{\mathrm{e}}$

$15.9 \%$ (10)

0.167

$7.9 \%$ (5)

$0.827^{\mathrm{e}}$

$1.6 \%$ (1)

$0.999^{\mathrm{e}}$

$1.6 \%(1)$

$0.999^{\mathrm{e}}$

$66.7 \%(40)$

0.408

$20.0 \%$ (12)

0.932

$13.3 \%(8)$

0.265

$20.0 \%$ (12)

$<0.001$

$84.1 \%(53)$

$<0.001$

Only frequencies for all falls $>2 \%$ are displayed

${ }^{\text {a }}$ Differences assessed by Pearson chi-square unless otherwise specified

${ }^{\mathrm{b}}$ Excludes one fall where information was unknown

"Excludes 10 non-hospitalised "night" falls who reported lighting was "not applicable"

${ }^{\mathrm{d}}$ High risk activities include falling down stairs or missing a step $(n=76)$, falling in a hole $(n=20)$, falling from a ladder or chair $(n=14)$, falling from bicycle $(n=4)$

${ }^{\mathrm{e}}$ Fisher's exact rather than Pearson chi-square

${ }^{\mathrm{f}}$ Displacement from a quiet place is "getting up from bed or chair" + "rushing..." + "sitting" + "standing"

g Excludes 15 responses of "unknown"

${ }^{\mathrm{h}}$ Excludes 17 responses of "unknown" 
Most falls involved falling forward irrespective of the injury category (59 vs. 62 vs. $63 \%$, no injury vs. "fracture" vs. non-fracture injury, respectively; $p=0.390$ ). Compared to women who fell only once during the observation time, women who fell at least two times were more likely to have $2+$ injuries per fall (odds ratio of $2+$ injuries, adjusting for age: 1.70; Table 5). This association remained when also adjusting for history of previous fracture (odds ratio of $2+$ injuries: 1.73; Table 5).

\section{Treatment of injuries from all falls}

Fallers did not seek treatment in almost 70\% ( $n=826 / 1195)$ of falls; however, a doctor was consulted in $9 \%$ of falls without injury $(n=34 / 374$; Table 4$)$. No treatment was sought in $65 \%$ of non-fracture injurious falls $(n=489 / 758)$. The faller was hospitalised in $5 \%$ of injurious falls without fracture and in $40 \%$ of falls with fracture(s) (Table 4$)$.

The time of fall (day/night) was not associated with consultation with a doctor, use of x-ray or having physiotherapy, stitches or injury dressing $(p=0.215)$.

\section{Falls associated with hospitalisation}

The most common characteristics of falls that resulted in a faller being admitted to hospital were inability to get up on one's own following the fall (84\%), the fall occurring during the day $(71 \%)$, indoors (62\%) and in the fallers' own home (62\%; Table 2). When several categories of fall-related activity were grouped under the heading "displacement from a quiet position", this contributed $24 \%$ of hospitalised falls compared to $13 \%$ of non-hospitalised falls. However, these fallers were more likely to be older (odds ratio adjusted for multiple falls within an individual: 1.07 [1.03, 1.11], $p=0.007$; mean age [SD]: 78.8 [4.8] vs. 80.3 [5.3], respectively). When adjusted for age and night/day time fall, "displacement from a quiet place" was no longer a significant predictor of hospitalisation ( $p=0.138$; Table 5). Falls that were associated with a loss of balance were three times more likely to result in the faller being hospitalised (OR 3.06, 95\% CI 1.76, 5.32, adjusted for age and within-person clustering of falls; Table 5).

The proportion of hospitalised falls that involved selfreported "blacking out" was higher than those that were not hospitalised ( 20 vs. $1 \% ; p<0.001$, Table 2). Although indoor falls were associated with a twofold increased likelihood of hospital admission (OR 1.87, 95\% CI 1.09, 3.24, adjusted for age and within-person clustering of falls; Table 5), this was explained by night time falls (OR 1.55, 95\% CI $0.88,2.72$, adjusted for age, multiple falls and day/night). Almost $30 \%$ of hospitalised falls occurred at night (Table 2). Despite no difference in the type of injury sustained for falls occurring at day or night, the likelihood of being hospitalised from a fall at night was 4.5 times greater than that of a daytime fall with adjustment for injury type and age of participants (OR 4.48, $95 \%$ CI $2.11,9.54)$.

\section{Fracture versus "non-fracture" falls}

Fracture(s) were sustained in $5 \%$ of all falls (Table 3 ). Of the 63 falls that resulted in fractures, the distribution of fracture sites was as follows: wrist $23 \%(n=15)$; humerus $17 \%$ $(n=11)$; vertebral $12 \%(n=8)$; hip $11 \%(n=7)$; other $38 \%$ ( $n=25$ consisting of ankle $n=7$; foot $n=3$; ribs $n=3$; patella, pelvis, forearm, lower leg, facial bones each $n=2$; hand $n=1$; clavicle $n=1$ ). There were 66 fracture sites as one fall resulted

Table 3 Prevalence of single and multiple injuries (self-reported; fractures radiologically confirmed)

\begin{tabular}{|c|c|c|c|c|c|}
\hline & $\begin{array}{l}\text { Fracture } \\
n=63 \text { falls }\end{array}$ & $\begin{array}{l}\text { Muscle strain } \\
n=275 \text { falls }\end{array}$ & $\begin{array}{l}\text { Bruising } \\
n=581 \text { falls }\end{array}$ & $\begin{array}{l}\text { Abrasion } \\
n=183 \text { falls }\end{array}$ & $\begin{array}{l}\text { "Other" injury } \\
n=27 \text { falls }\end{array}$ \\
\hline \multicolumn{6}{|c|}{ Prevalence of injuries - (821/1195 falls resulted in at least one type of injury) } \\
\hline - By total falls $(n=1195)$ & $5.3 \%$ & $23.0 \%$ & $48.6 \%$ & $15.3 \%$ & $2.3 \%$ \\
\hline - By injurious falls $(n=821)$ & $7.7 \%$ & $33.5 \%$ & $70.7 \%$ & $22.3 \%$ & $3.3 \%$ \\
\hline Single injury only (\% of each injury type) & $49.2 \%(31 / 63)$ & $16.4 \%(45 / 275)$ & $49.4 \%(287 / 581)$ & $36.6 \%(67 / 183)$ & $40.7 \%(11 / 27)$ \\
\hline \multicolumn{6}{|c|}{ Prevalence of multiple injuries (\% by column heading injury) } \\
\hline Fracture & & $2.2 \%(6 / 275)$ & $3.6 \%(21 / 581)$ & $2.2 \%(4 / 183)$ & $3.7 \%(1 / 27)$ \\
\hline Muscle strain & $9.5 \%(6 / 63)$ & & $32.2 \%(187 / 581)$ & $18.6 \%(34 / 183)$ & $11.1 \%(3 / 27)$ \\
\hline Bruising & $33.3 \%(21 / 63)$ & $68.0 \%(187 / 275)$ & & $41.5 \%(76 / 183)$ & $37.0 \%(10 / 27)$ \\
\hline Abrasion & $6.4 \%(4 / 63)$ & $12.4 \%(34 / 275)$ & $13.1 \%(76 / 581)$ & & $7.4 \%(2 / 27)$ \\
\hline "Other" injury" & $1.6 \%(1 / 63)$ & $1.1 \%(3 / 275)$ & $1.7 \%(10 / 581)$ & $1.1 \%(2 / 183)$ & \\
\hline
\end{tabular}

Table 3 displays the injuries rather than the number of falls. Of the 1195 falls, 374 did not result in injury and 821 falls resulted in at least one injury; $441 /$ 821 falls resulted in a single injury and 380/821 falls resulted in more than one injury

${ }^{a}$ Other injuries include 13 unconfirmed fractures and injuries including broken nose, concussion, sprained ankle. At study completion, 36\% ( $n=323 /$ 887) of women reported taking daily aspirin: $38 \%$ of fallers who sustained at least one fall with bruising vs. $39 \%$ of fallers without bruising vs. $33 \%$ of non-fallers reported taking daily aspirin 
Table 4 Treatment of fall injuries $(\%(n))$

\begin{tabular}{lccccccc}
\hline & $\begin{array}{l}\text { All falls } \\
n=1195\end{array}$ & $\begin{array}{l}\text { No injury } \\
n=374 \text { falls }\end{array}$ & $\begin{array}{l}\text { Fracture } \\
n=63 \text { falls }\end{array}$ & $\begin{array}{l}\text { Muscle strain } \\
n=275 \text { falls }\end{array}$ & $\begin{array}{l}\text { Bruising } \\
n=581 \text { falls }\end{array}$ & $\begin{array}{l}\text { Abrasion } \\
n=183 \text { falls }\end{array}$ & $\begin{array}{l}\text { "Other” injury } \\
n=27 \text { falls }\end{array}$ \\
\hline $\begin{array}{l}\text { No treatment } \\
\quad \text { (including no doctor visit) }\end{array}$ & $69.1 \%(826)$ & $\begin{array}{l}90.1 \% \\
(337 / 374)\end{array}$ & 0 & $51.3 \%(141 / 275)$ & $64.2 \%(373 / 581)$ & $54.6 \%$ & $25.9 \%(7 / 27)$ \\
Saw a doctor & $29.8 \%(356)$ & $9.1 \%(34 / 374)$ & $100 \%(63 / 63)$ & $47.8 \%(131 / 275)$ & $35.0 \%(203 / 581)$ & $42.1 \%(77 / 183)$ & $70.4 \%(19 / 27)$ \\
Hospitalisation & $5.3 \%(63)$ & $0.8 \%(3 / 374)$ & $39.7 \%(25 / 63)$ & $5.5 \%(15 / 275)$ & $5.2 \%(30 / 581)$ & $6.6 \%(12 / 183)$ & $22.2 \%(6 / 27)$ \\
X-ray/medical imaging & $9.4 \%(112)$ & $0.5 \%(2 / 374)$ & $100 \%(63 / 63)$ & $12.4 \%(34 / 275)$ & $9.1 \%(53 / 581)$ & $6.6 \%(12 / 183)$ & $40.7 \%(11 / 27)$ \\
Physiotherapy & $2.3 \%(27)$ & $0.8 \%(3 / 374)$ & $11.1 \%(7 / 63)$ & $6.2 \%(17 / 275)$ & $1.9 \%(11 / 581)$ & 0 & 0 \\
Stitches & $1.0 \%(12)$ & 0 & 0 & $1.1 \%(3 / 275)$ & $1.2 \%(7 / 581)$ & $6.6 \%(12 / 183)$ & $3.7 \%(1 / 27)$ \\
Injury dressing & $4.2 \%(50)$ & 0 & 0 & $4.7 \%(13 / 275)$ & $4.0 \%(23 / 581)$ & $23.0 \%(42 / 183)$ & $7.4 \%(2 / 27)$ \\
\hline
\end{tabular}

The sum of the falls in the heading includes more than $n=1195$ as women could report more than one injury and each injury could result in multiple treatments/examinations

${ }^{a}$ Other injuries include 13 unconfirmed fractures and injuries including broken nose, concussion, sprained ankle

b Two responses "unknown"

in two fracture sites and one fall resulted in three fracture sites. There was no difference in the likelihood of fracture between night and day (OR $1.09,95 \%$ CI $0.48,2.46)$. Only $13 \%$ of "fracture falls" occurred at night $(n=8 / 63)$. Women who fell and fractured during the observational period had a higher median rate of falling (median falls per annum (IQR): 1.20 $(0.63,2.41)$ vs. $0.60(0,1.20)$ "fracture" fallers [women who sustained fracture(s) from fall] vs. "non-fracture" fallers).

Women's age and body mass index did not differ between "fracture falls" and "non-fracture falls" $(p=0.567 ; p=0.680$, respectively).

Approximately one third of all participants reported a previous fracture since the age of 50 but this proportion was higher in fallers with fracture (54 vs. $35 \%$, fracture faller vs. non-fracture faller, $p=0.004)$. A higher proportion of "fracture falls" occurred away from home ( 52 vs. 41 vs. $32 \%$, "fracture falls" vs. "non-fracture injury falls" vs. "no injury" falls, respectively; $p=0.002$, Fig. 2a). Consistent with

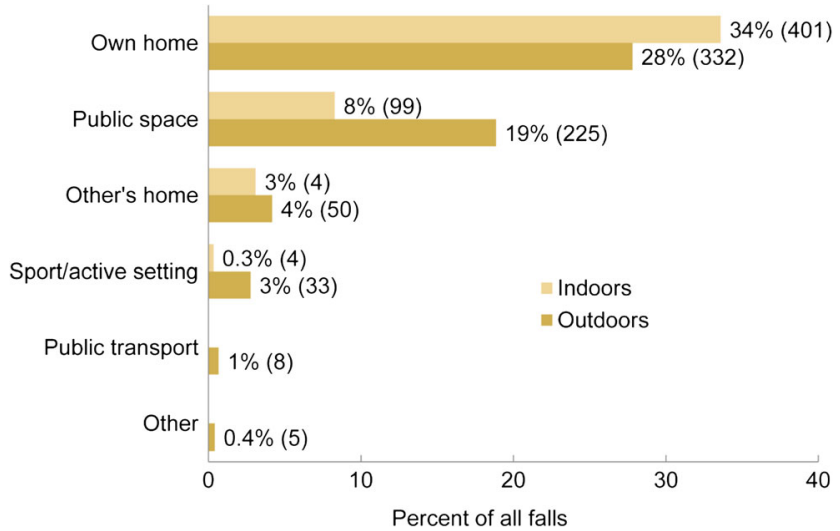

Fig. 1 Location of falls according to whether they occurred indoors or outdoors (falls $n=1194$, excludes 1 fall with "unknown" location). Public spaces include street, car park or kerb ( $n=117$ falls), shops or restaurant ( $n=62$ falls), public building, e.g. church ( $n=28$ falls), beach ( $n=20$ falls $)$, park $(n=16$ falls $)$ all falls, the majority of "fracture falls" occurred while the participant was walking $(65 \%, n=41 / 63)$. The activity of the participant at the time of the fall does not appear to be associated with the injury outcome $(p=0.324)$.

"Fracture falls" were commonly associated with slipping rather than tripping ( 40 vs. $10 \%$ slipping vs. tripping, respectively; Fig. 2b). There was a trend for "falls with fracture" to be precipitated by a warning sign such as feeling unsteady or unwell (33 vs. 22 vs. $20 \%$, "fracture" fall vs. non-fracture fall vs. non-injury, respectively, $p=0.062$ ).

\section{Discussion}

In our cohort of older women, there were few differences in precipitants and environmental factors between injurious and non-injurious falls. Approximately one third of all falls were associated with no injury, one third of fallers reported a single injury and a third reported multiple injuries. Women's age or body mass index was not associated with the injury status of a fall. Bruising was the most common self-reported injury but prevalence of bruising did not differ between those taking or not taking aspirin. Falls associated with fracture and/or hospital admission represent only $8.5 \%$ of all falls and almost $70 \%$ of falls do not come to medical attention. Our findings that (1) the falls rate is 85 per 100 person-years among older Australian women with (2) only 1 in 20 fall cases resulting in hospital admission is consistent with other data [3].

The $32 \%$ falls rate in our study sample is within the range of most observational studies done in the 1980s and 1990s internationally, where rates of 21 to $49 \%$ were reported [16, 26-28]. These cohorts were also community-dwelling older people with prospective ascertainment of falls. Despite an increased focus on falls prevention over the past 20 years, the fall rate in this study is virtually the same as two previous Australian studies that used retrospective falls ascertainment 
Fig. 2 a Location of falls by injury category (non-frac refers to non-fracture injury). Bars refer to differences between groups, chisquare, $p<0.05$. b Precipitant of falls by injury category. Different superscripts refer to differences between groups, chi-square, $p<0.05$
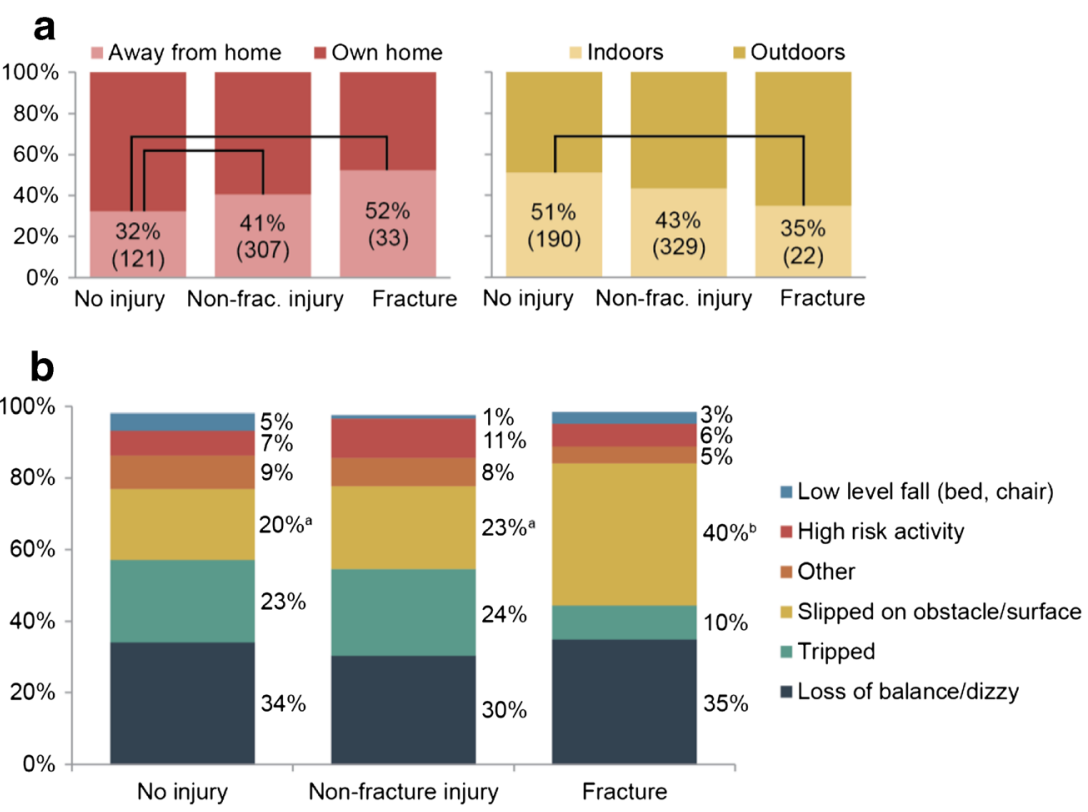

Table 5 Odds ratio (OR) and 95\% CI for hospitalisation resulting from a fall ${ }^{\text {a }}$ and likelihood of sustaining multiple injuries in those participants with multiple falls ${ }^{\mathrm{a}, \mathrm{b}}$

OR

$\begin{array}{ccc}1.9 & 1.0,3.6 & 0.052 \\ 1.6 & 0.9,3.1 & 0.138 \\ 2.8 & 1.5,5.3 & 0.001 \\ & & \\ 3.1 & 1.8,5.3 & <0.0001 \\ & & 0.024 \\ 1.9 & 1.1,3.2 & 0.128 \\ 1.6 & 0.9,2.7 & 0.002 \\ 2.7 & 1.4,5.0 & 0.010 \\ 2.6 & 1.3,5.5 & 0.002 \\ 3.4 & 1.6,7.5 & <0.0001 \\ & & 0.001\end{array}$

Odds of hospitalisation

Model 1

Fall "Displacement from quiet position" (vs. not)

Model 2

Fall "Displacement from quiet position" (vs. not)

Fall occurring at night (vs. during the day time)

Model 1

Fall associated with loss of balance (vs. any other circumstance)

Model 2

Fall occurring indoors (vs. outdoors)

Model 3 (Model $2+$ time of day)

Fall occurring indoors (vs. outdoors)

Fall occurring at night (vs. during the day time)

Model 4 (Model $3+$ injury type)

Fall occurring indoors (vs. outdoors)

Fall occurring at night (vs. during the day time)

Injury type (vs. no injury sustained from fall)

- Fracture from fall

- Non-fracture injury

Odds of sustaining multiple injuries

Number of falls per individual vs. number of injuries per fall ${ }^{\mathrm{a}, \mathrm{b}}$

Multiple (2+) injuries in those with multiple (2+) falls

1.70

$1.14,2.52$

0.0096

Multiple (2+) injuries in those with multiple (2+) falls, adjusted for history of previous fracture

1.73

$1.16,2.57$

0.0077

Italics refers to $p$ value less than 0.05

${ }^{a}$ Multilevel logistic regression accounting for multiple falls within an individual. All models are adjusted for age

${ }^{\mathrm{b}}$ Compared to women who fell only once during the observation time, women who fell at least two times were more likely to have $2+$ injuries per fall.

This association remained when also adjusting for history of previous fracture (odds ratio of $2+$ injuries: $1.73(95 \%$ CI 1.16, 2.57), $p=0.0077$ ) 
and reported fall rates of 31 and $34 \%[18,29]$. We have previously reported retrospective ascertainment of falls to have $77 \%$ sensitivity and $94 \%$ specificity [30]. Our recruitment using an algorithm to identify community-dwelling women at higher risk of falls and/or fracture may have minimised the "healthy volunteer" bias often associated with these studies.

We report that $5 \%$ of all falls result in fracture. This is slightly lower than international estimates that included falls among both community-dwelling elders and residents of aged care facilities $(8$ to $25 \%$ [31, 32]). The fracture rate in our cohort is slightly higher than that reported two decades ago for the same region's population of women aged at least 70 years (3\% per annum [21]). We are unable to establish if the falls rate has decreased over the past 20 years, consistent with a 15 to $20 \%$ decline in hip fracture rates in Australia and elsewhere $[8,33]$. Hill and colleagues have suggested that an increased focus on falls prevention has not reduced the magnitude of falls burden among older Australians [34].

Four out of five hospitalised fallers reported they did not "black out" and we did not identify precipitants or environmental features that distinguished between falls that resulted in hospitalisation and those that did not. Falls grouped into the category of "displacement from a quiet position" contributed almost double the proportion of hospitalised falls to non-hospitalised falls. However, this was not significant when adjusted for night time falls. Almost two thirds of all falls occurred in the faller's home and although $88 \%$ of falls occurred during the day, night time falls were 4.5 times more likely to result in hospitalisation. An alternate pathway aiming to avoid hospital presentation for older "night fallers" without injury identifies a potential future cost-saving. Earlier findings in the USA report 50\% of fall injury events that occurred at home and required hospital admission resulted in the person being discharged to a nursing home [35].

Although hospital admission is a key cost driver and falls can be the most common cause of injury treated in emergency departments [36], fallers admitted to hospital are the tip of the iceberg. Cost-effective programs require broad dissemination, adoption and implementation to reduce the burden of falls [36]. Our findings suggest the diversity of falls characteristics is likely to hamper cost-effective prevention [37]. Furthermore, an underestimation of the rate of injurious falls that remain untreated can inflate the "cost per fall" estimates [38]. This can translate to an overestimation of the cost effectiveness ratio of a falls prevention program. Haines and colleagues recommend "cost of falls per person" as an alternative. Our finding that almost $70 \%$ of all falls are untreated supports this recommendation.

Strategies to improve the balance and maintain muscle mass of older adults are likely to be expensive to implement on a wide scale but have appeal due to the applicability to decrease falls across a range of environments and the potential improvement in general health of older people. Approximately one third of falls in our cohort were precipitated by a self-reported loss of balance. Our cohort is likely to be less healthy than volunteers in a previous Australian study that suggests women reporting a single fall have minimal risk for further falls [16]. Hill and colleagues propose that falls among healthy, older women are often not attributable to balance and mobility impairments but can be attributed to environmental factors [16]. We have previously reported that declines in gait performance over several years in this cohort are associated with recurrent falls status [39]. Although a higher proportion of all falls occurred at home in our cohort compared to Hill and colleagues' cohort, few falls were associated with rushing, reaching up or falling out of bed.

The study results support the value of incorporating an index of falls risk into algorithms of fracture risk assessment and treatment thresholds, particularly since multiple fallers were more likely to sustain multiple injuries. However, the findings highlight the difficulties in strategies aiming to reduce fracture risk through falls prevention. As only 1 in 20 falls results in fracture(s), a falls prevention program/drug with $20 \%$ efficacy means that only one fracture would be averted for every 100 women treated (not allowing for compliance issues) with a $20 \%$ reduction in the falls rate. This equates to a $1 \%$ efficacy for fracture risk reduction.

The limitations include that the study did not include men; only fractures and hospital admissions were confirmed following self-report of injuries; injuries were not categorised by medical severity; and falls could not be categorised by presentation at an emergency department. More detail on the time of day and whether the participant lived alone or with other family would also have contributed to the discussion. To avoid a healthy volunteer bias, recruitment of participants was restricted to those who reached an algorithm score indicting higher risk of falls and/or fracture [23]. However, there was a trend towards a higher proportion of those "lost to follow-up" to have a history of previous fracture.

A particular strength of this study is the thorough ascertainment of falls. All fallers were interviewed by phone upon receipt of the monthly falls calendar and fall circumstances were documented using a standardised questionnaire administered by trained research staff.

Our findings demonstrate the significant diversity of precipitants and environment where falls commonly occur among a large cohort of older community-dwelling women. Falls associated with significant injury, particularly those resulting in fracture and/or hospital admission, represent only a very small proportion of all falls $(8.5 \%)$ yet their characteristics are indistinguishable from falls not coming to medical attention and incurring no apparent cost to the health system. While falls risk may be a relevant indicator of both fracture risk and risk of injury requiring hospital admission, falls prevention may ideally be targeted to decreasing the prevalence of frailty of the faller rather than targeted to the environment.

Acknowledgements The study was supported by project grant no. 251682 from the National Health and Medical Research Council and by the Australian Government Department of Health and Ageing. 


\section{Compliance with ethical standards}

Conflicts of interest Kerrie Sanders has received a research grant from Merck Pty Ltd. (unrelated project) and speaker honorarium from Sanofi and Amgen. Karen Lim, Amanda L Stuart, Ashley Macleod, David Scott, Geoffrey C Nicholson and Lucy Busija have no conflicts of interest.

Open Access This article is distributed under the terms of the Creative Commons Attribution-NonCommercial 4.0 International License (http:// creativecommons.org/licenses/by-nc/4.0/), which permits any noncommercial use, distribution, and reproduction in any medium, provided you give appropriate credit to the original author(s) and the source, provide a link to the Creative Commons license, and indicate if changes were made.

\section{References}

1. Australian Institute of Health and Welfare A (2016) Australian Burden of Disease Study: impact and causes of illness and death in Australia 2011. vol Australian Burden of Disease series. Canberra

2. Bradley CA (2013) Trends in hospitalisations due to falls by older people, Australia 1999-00 to 2010-11. Injury research and statistics. Canberra

3. AIHW, Bradley C (2013) Hospitalisations due to falls by older people, Australia 2009-10. Injury research and statistics series

4. Australian Institute of Health and Welfare (2011) Australian hospital statistics 2009-10. Health services series no. 40. Cat. no. HSE 107. AIHW. http://www.aihw.gov.au/publication-detail/?id= 10737418863. Accessed 11 January 2017

5. Li F, Eckstrom E, Harmer P, Fitzgerald K, Voit J, Cameron KA (2016) Exercise and fall prevention: narrowing the research-topractice gap and enhancing integration of clinical and community practice. J Am Geriatr Soc 64(2):425-431. doi:10.1111/jgs.13925

6. Jarvinen TL, Sievanen H, Khan KM, Heinonen A, Kannus P (2008) Shifting the focus in fracture prevention from osteoporosis to falls. BMJ 336(7636):124-126. doi:10.1136/bmj.39428.470752.AD

7. Diez-Perez A, Adachi JD, Adami S, Anderson FA Jr, Boonen S, Chapurlat R, Compston JE, Cooper C, Gehlbach SH, Greenspan SL, Hooven FH, LaCroix AZ, Nieves JW, Netelenbos JC, Pfeilschifter J, Rossini M, Roux C, Saag KG, Silverman S, Siris ES, Wyman A, Rushton-Smith SK, Watts NB, Global Longitudinal Study of Osteoporosis in Women I (2014) Risk factors for treatment failure with antiosteoporosis medication: the Global Longitudinal Study of Osteoporosis in Women (GLOW). J Bone Miner Res 29(1):260-267. doi:10.1002/jbmr.2023

8. Crisp A, Dixon T, Jones G, Cumming RG, Laslett LL, Bhatia K, Webster A, Ebeling PR (2012) Declining incidence of osteoporotic hip fracture in Australia. Arch Osteoporos 7:179-185. doi:10.1007/ s11657-012-0095-y

9. Sanders KM, Nicholson GC, Ugoni AM, Pasco JA, Seeman E, Kotowicz MA (1999) Health burden of hip and other fractures in Australia beyond 2000. Projections based on the Geelong Osteoporosis Study. Med J Aust 170(10):467-470

10. Aspray TJ (2013) New horizons in fracture risk assessment. Age Ageing 42(5):548-554. doi:10.1093/ageing/aft095

11. Nayak S, Edwards DL, Saleh AA, Greenspan SL (2014) Performance of risk assessment instruments for predicting osteoporotic fracture risk: a systematic review. Osteoporos Int 25(1):23-49. doi:10.1007/s00198-013-2504-5

12. FitzGerald G, Compston JE, Chapurlat RD, Pfeilschifter J, Cooper C, Hosmer DW Jr, Adachi JD, Anderson FA Jr, Diez-Perez A,
Greenspan SL, Netelenbos JC, Nieves JW, Rossini M, Watts NB, Hooven FH, LaCroix AZ, March L, Roux C, Saag KG, Siris ES, Silverman S, Gehlbach SH (2014) Empirically based composite fracture prediction model from the Global Longitudinal Study of Osteoporosis in Postmenopausal Women (GLOW). J Clin Endocrinol Metab 99(3):817-826. doi:10.1210/jc.2013-3468

13. Rubin KH, Friis-Holmberg T, Hermann AP, Abrahamsen B, Brixen K (2013) Risk assessment tools to identify women with increased risk of osteoporotic fracture: complexity or simplicity? A systematic review. J Bone Miner Res 28(8):1701-1717. doi:10.1002/jbmr. 1956

14. Gates S, Smith LA, Fisher JD, Lamb SE (2008) Systematic review of accuracy of screening instruments for predicting fall risk among independently living older adults. J Rehabil Res Dev 45(8):11051116

15. Waldron N, Hill AM, Barker A (2012) Falls prevention in older adults assessment and management. Aust Fam Physician 41(12): 930-935

16. Hill K, Schwarz J, Flicker L, Carroll S (1999) Falls among healthy, community-dwelling, older women: a prospective study of frequency, circumstances, consequences and prediction accuracy. Aust N Z J Public Health 23(1):41-48

17. Tinetti M, Williams C (1997) Falls, injuries due to falls, and the risk of admission to a nursing home. N Engl J Med 337:1279-1284

18. Lord SR, Ward JA, Williams P, Anstey KJ (1993) An epidemiological study of falls in older community-dwelling women: the Randwick falls and fractures study. Aust J Public Health 17(3): 240-245

19. Carpenter CR, Avidan MS, Wildes T, Stark S, Fowler SA, Lo AX (2014) Predicting geriatric falls following an episode of emergency department care: a systematic review. Acad Emerg Med 21(10): 1069-1082. doi:10.1111/acem. 12488

20. Barker AL, McNeil JJ, Seeman E, Ward SA, Sanders KM, Khosla S, Cumming RG, Pasco JA, Bohensky MA, Ebeling PR, Woods RL, Lockery JE, Wolfe R, Talevski J, the ASPREE Investigator Group (2015) A randomised controlled trial of low-dose aspirin for the prevention of fractures in healthy older people: protocol for the ASPREE-Fracture substudy. Inj Prev. doi:10.1136/ injuryprev-2015-041655

21. Sanders KM, Seeman E, Ugoni AM, Pasco JA, Martin TJ, Skoric B, Nicholson GC, Kotowicz MA (1999) Age- and gender-specific rate of fractures in Australia: a population-based study. Osteoporos Int 10(3):240-247. doi:10.1007/s001980050222

22. Sanders KM, Stuart AL, Williamson EJ, Simpson JA, Kotowicz MA, Young D, Nicholson GC (2010) Annual high-dose oral vitamin D and falls and fractures in older women: a randomized controlled trial. JAMA 303(18):1815-1822. doi:10.1001/jama.2010. 594

23. Sanders KM, Stuart AL, Merriman EN, Read ML, Kotowicz MA, Young D, Taylor R, Blair-Holt I, Mander AG, Nicholson GC (2009) Trials and tribulations of recruiting 2,000 older women onto a clinical trial investigating falls and fractures: Vital D study. BMC Med Res Methodol 9(1):78

24. Sanders KM, Stuart AL, Williamson EJ, Jacka FN, Dodd S, Nicholson G, Berk M (2011) Annual high-dose vitamin D3 and mental well-being: randomised controlled trial. Br J Psychiatry 198(5):357-364. doi:10.1192/bjp.bp.110.087544

25. Lamb SE, Jorstad-Stein EC, Hauer K, Becker C, Prevention of Falls Network E, Outcomes Consensus G (2005) Development of a common outcome data set for fall injury prevention trials: the Prevention of Falls Network Europe consensus. J Am Geriatr Soc 53(9):1618-1622. doi:10.1111/j.1532-5415.2005.53455.x

26. Gabell A, Simons MA, Nayak US (1985) Falls in the healthy elderly: predisposing causes. Ergonomics 28(7):965-975. doi:10.1080/ 00140138508963219 
27. Tinetti ME, Speechley M, Ginter SF (1988) Risk factors for falls among elderly persons living in the community. N Engl J Med 319(26):1701-1707. doi:10.1056/NEJM198812293192604

28. Campbell AJ, Borrie MJ, Spears GF (1989) Risk factors for falls in a community-based prospective study of people 70 years and older. J Gerontol 44(4):M112-M117

29. Dolinis J, Harrison JE, Andrews GR (1997) Factors associated with falling in older Adelaide residents. Aust N Z J Public Health 21(5): $462-468$

30. Sanders KM, Stuart AL, Scott D, Kotowicz MA, Nicholson GC (2015) Validity of 12-month falls recall in community-dwelling older women participating in a clinical trial. Int $\mathrm{J}$ Endocrinol 2015:210527. doi: $10.1155 / 2015 / 210527$

31. Nurmi I, Luthje P (2002) Incidence and costs of falls and fall injuries among elderly in institutional care. Scand J Prim Health Care 20(2):118-122

32. Rubenstein LZ (2006) Falls in older people: epidemiology, risk factors and strategies for prevention. Age Ageing:35 Suppl 2, ii37-35 Supii41. doi:10.1093/ageing/afl084

33. Stevens JA, Rudd RA (2013) The impact of decreasing U.S. hip fracture rates on future hip fracture estimates. Osteoporos Int 24(10):2725-2728. doi:10.1007/s00198-013-2375-9

34. Hill K, Kerse N, Lentini F, Gilsenan B, Osborne D, Browning C, Harrison J, Andrews G (2002) Falls: a comparison of trends in community, hospital and mortality data in older Australians. Aging Clin Exp Res 14(1):18-27

35. Sattin RW, Lambert Huber DA, DeVito CA, Rodriguez JG, Ros A, Bacchelli S, Stevens JA, Waxweiler RJ (1990) The incidence of fall injury events among the elderly in a defined population. Am J Epidemiol 131(6):1028-1037

36. Stevens JA, Voukelatos A, Ehrenreich H (2014) Preventing falls with Tai Ji Quan: a public health perspective. J Sport Health Sci 3(1):21-26. doi:10.1016/j.jshs.2013.10.002

37. Heinrich S, Rapp K, Rissmann U, Becker C, Konig HH (2010) Cost of falls in old age: a systematic review. Osteoporos Int 21(6):891902. doi:10.1007/s00198-009-1100-1

38. Haines TP, Nitz J, Grieve J, Barker A, Moore K, Hill K, Haralambous B, Robinson A (2013) Cost per fall: a potentially misleading indicator of burden of disease in health and residential care settings. J Eval Clin Pract 19(1):153-161. doi:10.1111/j.13652753.2011.01786.x

39. Scott D, McLaughlin P, Nicholson GC, Ebeling PR, Stuart AL, Kay D, Sanders KM (2015) Changes in gait performance over several years are associated with recurrent falls status in communitydwelling older women at high risk of fracture. Age Ageing 44(2): 287-293. doi:10.1093/ageing/afu169 